\title{
Accidental Migration of a Guide Wire during Femoral Venous Catheterization for Hemodialysis: A Case Report
}

\author{
Faye Moustapha*, Cisse Mouhamadou Moustapha, Faye Maria, Daher Abdoul Karim Omar, \\ Lemrabott Ahmed Tall, Fall Khodia, Sakho Binta, Keita Alex, Mbengue Mansour, Niang Abdou, \\ Diouf Boucar, Ka Elhadji Fary
}

Department of Nephrology, Aristide Le Dantec, Cheikh Anta Diop University, Dakar, Senegal

Email: ^mfayeintaida@gmail.com, mfayemed@yahoo.fr

How to cite this paper: Moustapha, F., Moustapha, C.M., Maria, F., Omar, D.A.K., Tall, L.A., Khodia, F., Binta, S., Alex, K., Mansour, M., Abdou, N., Boucar, D. and Fary, K.E. (2018) Accidental Migration of a Guide Wire during Femoral Venous Catheterization for Hemodialysis: A Case Report. Open Journal of Nephrology, 8, 38-41.

https://doi.org/10.4236/ojneph.2018.82005

Received: April 26, 2018

Accepted: June 9, 2018

Published: June 12, 2018

Copyright $\odot 2018$ by authors and Scientific Research Publishing Inc. This work is licensed under the Creative Commons Attribution International License (CC BY 4.0).

http://creativecommons.org/licenses/by/4.0/

\section{(c) (i) Open Access}

\begin{abstract}
Femoral venous catheterization is the most used technic in emergency hemodialysis. Some uncommon mechanical complications can occur during a catheterization. We report the case of an accidental migration of a guide wire during the placement of a hemodialysis femoral catheter. The case of a patient admitted in the nephrology department at Aristide Le Dantec University Hospital for malignant hypertension was investigated. Emergency hemodialysis was indicated. Surgical extraction of the metal guide has been performed and the outcome was favorable.
\end{abstract}

\section{Keywords}

Hemodialysis, Catheter, Complication, Guide Wire Migration

\section{Introduction}

Femoral venous catetherism is the most used vascular access for emergency hemodialysis [1]. The main complications of this technic are arterial puncture, hematoma, infections, femoral or iliac venous thrombosis [2].

The migration of the guide wire into the venous circulation is a rare complication that can occur with this technic. We report a case of accidental migration of the guide wire during placement of the hemodialysis femoral catheter.

\section{Case Observation}

We report the case of a 30-year-old male patient admitted in the nephrology department at Aristide Le Dantec University Hospital. His symptoms were nausea, 
abdominal pain, vomiting, anorexia, headache and blurred vision.

Physical examination revealed clinical anemia, tachycardia with a pulse rate of $120 \mathrm{p} / \mathrm{min}$. and hypertension with a blood pressure of 213/150 $\mathrm{mmHg}$ and hypertensive retinopathy stage 3 of Kirkendal classification.

Biological investigations revealed normochromic normocytic anemia with a hemoglobin rate of $5.3 \mathrm{~g} / \mathrm{dl}$, thrombocytopenia $136,000 / \mathrm{mm}^{3}$ no schistocytes, serum urea $3.6 \mathrm{~g} / \mathrm{l}$, serum creatinine $21.61 \mathrm{mg} / \mathrm{dl}$, serum sodium $120 \mathrm{mmol} / \mathrm{l}$ and serum potassium $5.2 \mathrm{mmo} / \mathrm{l}$. Ultrasound showed a normal aspect for both kidneys.

A diagnosis of the malignant hypertension complication of thrombotic microangiopathy and acute kidney failure was made.

Hemodialysis was indicated in an emergency. The femoral venous catheter was chosen as vascular access and placed by an internal nephrology.

The technique was performed as follows: The patient was made to lie on his back. Anatomical tracking of the femoral vein was done on the lower left side of the crural arcade, $2 \mathrm{~cm}$ below the femoral pulse. The vein was easily punctured. During dilation of the catheter inlet, the guide wire migrated into the bloodstream. The procedure was immediately stopped when the guide slid completely into the circulation. Radiography of the abdominal and the chest region revealed the position of the wire across the common iliac vein, the inferior cava vein and the right atrium up to the superior cava vein (Figure 1 and Figure 2). Anticoagulation was done with $100 \mathrm{UI} / \mathrm{kg}$ of enoxaparin. A surgical extraction of the guide wire under general anesthesia by incision of JALAGUIER and venotomy was performed on day 3 of the guide migration. The post-operative suites were simple. Radiography control confirms the absence of wire material.

\section{Discussion}

Prevalence of vein catheterism complications was estimated at $12 \%$ [2]. The femoral vein is now identified as a favorable location for central venous catheterization due to a high success rate and a lower incidence of serious complications [1]. However, this technic is a source of multiple early complications (hematoma, puncture of the artery) and late complications (infections, thrombosis of the femoral or iliac vein) [3] [4]. The success of this technic depends on attention and concentration as well as experience of the operator [2]. The migration of the guide wire is a rare mechanic complication. This might be the first case reported in Senegal. For this issue, Srivastava et al. identified some predictive factors: lack of experience, inattention, distracted senior supervisor, other suggests uncoordinated movement, patient shaking and a rather long guide [4]. In our case, it was the inattention while dilating vein. The main reported situation in the literature is during the catheter insertion [5] [6]. Some complications can occur when a guide migrates: rhythm or myocardial conduction disorders, perforation of the vessel or heart chamber, training of a loop in the vessel, tearing distal tip of the guide subsequently giving an embolism [4] [5] [6] [7]. None of these complications occurred in our patient. 


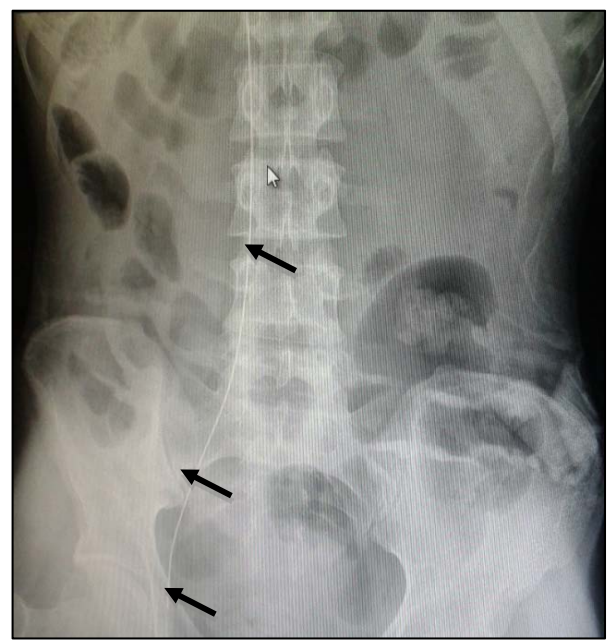

Figure 1. Guide wire in the femoral vein, iliac and inferior cava vein.

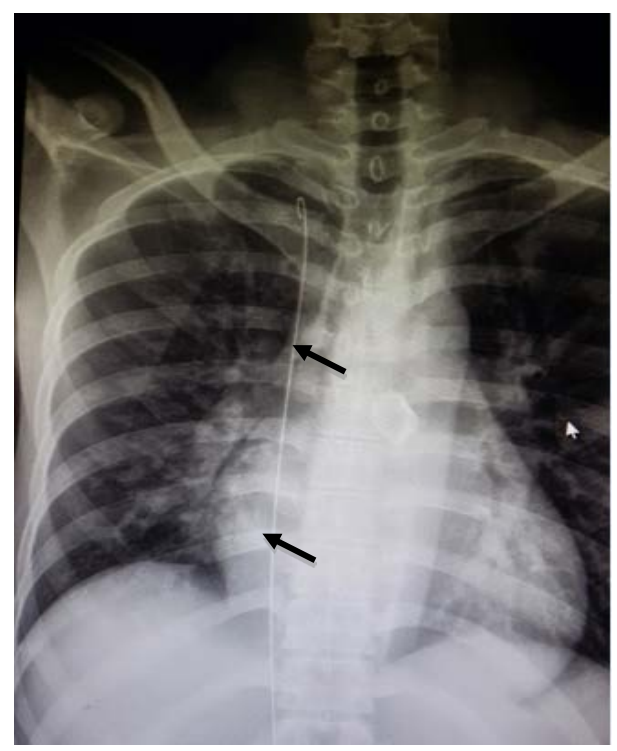

Figure 2. Guide wire in the right atrium and the superior cava vein.

A diagnosis of guide wire migration in venous circulation system can be made easy by standard radiography [2]. Guide removal can be performed surgically if radiologic assistance is unavailable, as was the case in ours.

\section{Conclusion}

Femoral vein catetherism is the most accesses procedure in emergency hemodialysis. Mechanical complications can be avoided using ultrasound and with an experimental operator.

\section{Conflicts of Interest}

The authors declare not to have any conflict of interest in relation to this article. 


\section{Ethical}

We declare that this paper was published after consent of the patient.

\section{References}

[1] El Bouazzaoui, A., Darkaoui, A., Houari, N., et al. (2010) Perforation iléale iatrogène: complication mécanique exceptionnelle de la pose du cathéter d'hémodialyse au niveau du site fémoral. Pan African Medical Journal, 5, 24.

[2] Brahim, B., Abderrahim, E.B., et al. (2014) Accidental Migration of a Guidewire during Femoral Venous Catheterization-A Case Report. iMedPub Journals, 6, 1-3.

[3] Schummer, W., Schummer, C., Gaser, E., et al. (2002) Loss of the Guide Wire: Mishap or Blunder? British Journal of Anaesthesia, 88, 144-146. https://doi.org/10.1093/bja/88.1.144

[4] Srivastav, R., Yadav, V., Sharma, D., et al. (2013) Loss of Guide Wire: A Lesson Learnt. Review of Literature. Journal of Surgical Technique and Case Report, 5 , 78-81. https://doi.org/10.4103/2006-8808.128732

[5] Abuhasna, S., Abdallah, D., Ur Rahman, M., et al. (2011) The Forgotten Guide Wire: A Rare Complication of Hemodialysis Catheter Insertion. Journal of Clinical Imaging Science, 1, 40. https://doi.org/10.4103/2156-7514.83397

[6] Khatami, M.R., Abbasi, R., Sadigh, G., et al. (2010) Guide Wire Migration during Femoral Vein Catheterization. Iranian Journal of Kidney Diseases, 4, 333-335.

[7] Tong, M.K.H. (2004) Misplacement of a Right Internal Jugular Vein Hemodialysis Catheter into the Mediastinum. Hong Kong Medical Journal, 10, 135-138. 